\section{Glaucoma: an area of darkness}

I am aware that that of all the previous subjects chosen by earlier speakers, only two were on the subject of glaucoma. However, the two previous lecturers, Sir Stewart Duke-Elder and Stephen Drance OC were of such great distinction that there was no sense of imbalance. However, it is timely to revisit the subject of glaucoma, hence the title of my talk: 'Glaucoma - an area of darkness'.

The Bowman lecture was named after the founder and first President of the Ophthalmic Society of the United Kingdom, the predecessor to our College, a man whose lifetime's achievements have been ably discussed by my predecessors. It is worth remembering that he was not only the founder but also an early benefactor of the College, whose annual donation of $£ 50$ per year was sufficient to pay for rental of premises in the Medical Society of London for the first years of the Society's existence.

William Bowman had Hospital appointments both at Kings College and Moorfields; I am fortunate to have shared this distinction with him. While at Kings, he was notable for his undergraduate teaching and one long address to medical students is preserved in his collected papers today. What is also preserved is his correspondence with Florence Nightingale, and he was able to send nurses from Kings to support her work in the Crimea.

His collected works show a profound interest in glaucoma, and this interest has encouraged me to address this subject. He was a close friend of von Graefe, and through him introduced the practice of iridectomy to UK ophthalmologists (his collected works include a translation from the German paper by von Graefe describing the operation, as well as a masterful put down of an Irish critic of the procedure). His friendship with Donders hastened the introduction of the ophthalmoscope into UK practice as well.

I will review our understanding and management of glaucoma. In doing so I will, in golfing terms, stick to the fairway and discuss primary (open angle) glaucoma, I will avoid the distractions of secondary or juvenile glaucoma
Received: 21 July 2008 Accepted in revised form: 21 July 2008 Published online: 12 September 2008 \begin{abstract}
Society, of which he was the first President, the Council shall, each year, or periodically, nominate some person to deliver a lecture Lecture', which shall consist of a critical resume of recent advances in ophthalmology ...'.

I am honoured to have been chosen to deliver this years Bowman lecture. In accepting the honour, I am humbled by knowledge that my predecessors constitute a roll call of the good and the great in our speciality. I did wonder upon my suitability to be considered among them, but decided that the Councils collective wisdom was far greater than mine.

Introduction
In 1883 the Council of the Ophthalmic Society of the United Kingdom honoured its founder inaugurating the Bowman Lectures. Its in recognition of Mr Bowman's distinguished scientific position in ophthalmology and other branches of Medicine, and in commemoration
\end{abstract}

Moorfields
London, UK

Fax: 02076086925

E-mail: rogerhitchings@ 
in so much as they (through small numbers) have relatively little impact on the visual health of our community. I will first look at concepts in existence in Bowman's time. Then I will look at issues current at the time of Duke Elder in 1956 and Drance in 1995. Then I will look at the changes that have taken place in the past 15 years before concluding with a forward look at today's challenges for tomorrow.

\section{Glaucoma in Bowman's time}

Bowman was one of the first to emphasize the importance of measuring intraocular pressure (IOP). His system of ocular palpation was developed to a high degree of sensitivity, allowing him to assign normal levels of eye pressure $(T)$ and varying levels of increased pressure $(T+1, T+2)$ to glaucomatous eyes.

He described the changes in IOP after iridectomy, and noted that in some cases a filtering cicatrix developed. He described the subconjunctival collection of aqueous, which in many cases remained 'discrete' but on occasion 'elevated' with a consequent risk of infection. He practised at the time of Bjerrum, whose description of the arcuate scotoma (from the Greek skotoun to darken, Skotos $=$ Darkness) has given me the title of my talk.

Glaucoma during Bowman's time remained an ill-defined subject, poorly sighted eyes with elevated pressure were designated glaucomatous, and those coming to post-mortem usually had angle closure, either primary or secondary. Significant discussion took place at the 1908 meeting of the OSUK when Dr Henderson, in his paper 'The anatomy of the so-called ligamentum pectinatum of the iris and its bearing on the physiology and the pathology of the eye', asserted that trabecular sclerosis impeded the outflow of (aqueous) fluid from the eye and caused elevated IOP. ${ }^{1}$ In the subsequent discussion this was refuted both by Lister and Coats who each supported angle closure as the (sole) cause of elevated IOP. Subsequent research confirmed his view, and elevated IOP in 'quiet' (ie not inflamed) eyes became the cause as well as an essential component of POAG. The concomitant development of gonioscopy allowed differentiation between open and closed angles in vivo.

\section{Glaucoma at the time of Sir Stewart Duke Elder}

Sir Stewart Duke Elder chose as his subject 'The aetiology of Simple Glaucoma'. ${ }^{2}$ It is worth remembering that in the 1950s 'Simple' referred to 'quiet' or uninflamed eyes, what we would call primary glaucoma in adult eyes today. In a wide ranging and remarkably prescient talk he looked at IOP control, noting the existence of an IOP controlling centre in the hypothalamus of the cat, and the physiology of aqueous outflow before discussing the vascular circulation of the optic nerve and the nature of visual field defects. A recurring theme of his presentation was that 'glaucoma' could occur in the absence of elevated IOP and that both the changes at the trabecular meshwork and at the optic nerve head would result from 'vaso or tissue sclerosis'. He was very determined to emphasize the concept of a sick eye in a sick body as well.

It is noteworthy that Duke Elder was a very late convert to the concept of pupil block. The concept of pupil block and its relief was first promulgated by Curran. ${ }^{3}$ Troncosco suggested that eyes with 'acute' or 'subacute' glaucoma an initially open angle closed later in the attack. ${ }^{4}$ Sugar concluded that the anterior chamber angle is open but narrow before an attack, but closed during an attack of congestive glaucoma. ${ }^{5}$ It was only the development and cure of the condition by iridectomy that the concept of pupil block was accepted. ${ }^{6}$

This approach was contested by Duke Elder, who until the 1950s maintained that the narrowness of the angle was caused by the congestion and followed the acute attack. ${ }^{7}$

\section{Glaucoma at the time of Stephen Drance}

Stephen Drance in his lecture observed the different morphometric appearances of the optic nerve in glaucoma and went on to look at the role of non-IOP causes of the disease. ${ }^{8}$ He stressed the morphometric and functional differences between high pressure and 'non-pressure-related' glaucoma asking us to consider alternative risk factors in the causation of this disease. Time of course has proved this latter point correct with the observation from incidence studies of low-baseline IOP and low-perfusion pressure in new glaucoma's. ${ }^{9,10}$

At the time of the Bowman lecture delivered by Drance a systematic review on Medical Evidence by Eddy and Billings ${ }^{11}$ had had profound effects on the medical community in general, and the glaucoma community in particular. Up until that time, topical hypotensive treatment had been prescribed on the basis that the IOP was elevated in a diseased eye, and that this was causal. The alternative that optic nerve disease and elevated IOP were part of the same problem was not countenanced. The article by Eddy and Billings reviewed the evidence that IOP reduction benefited glaucoma patients, and concluded that there was none. It followed from this article that the then current treatment guidelines and best practice were not based on evidence. Although denounced by clinicians, it alerted the glaucoma community of the need to develop end points other than IOP reduction as evidence for a treatment effect. This article helped generate the momentum that lead to the development of optic disc and visual function as 
outcome measures for randomized controlled trials (RCTs) of glaucoma treatment. It is the results from various RCTs using these outcome measures that have dominated glaucoma at the present time.

An early RCT comparing primary surgery with conventional treatment demonstrated better IOP control in the surgery group and suggested that this gave better visual field preservation in the primary surgery group. ${ }^{12}$ Another RCT commenced in 1983 was underway at Moorfields. The 'Primary treatment Trial' looked at IOP control and the long-term functional outcome after early surgery compared with laser and medicine in open-angle glaucoma. ${ }^{13}$ No patient had received any anti-glaucoma treatment before entry into the trial. The visual fields were assessed by suprathreshold perimetry using the Friedmann perimeter. Follow-up was for a minimum of 5 years. The results were reported in 1994. Primary surgery resulted in the lowest mean IOPs $(14.1 \mathrm{~mm} \mathrm{Hg}$, compared with $18.5 \mathrm{~mm} \mathrm{Hg}$ for both the laser and the medicine groups). It was shown that the fields deteriorated in patients in the medicine-treated group and to a lesser extent in patients in the laser-treated group, but not in patients in the surgery-treated group. Multivariate linear regression analysis showed that the difference in field changes between laser and surgical treatments could be explained entirely by the difference between the IOP values at 6 months between the two groups. The study demonstrated that long-term IOPs in the mid 'teens' could be obtained (with surgery) and suggested that this was the explanation for visual field survival.

The IOP but not the visual field results were later replicated by the CIGTS study. ${ }^{14,15}$

In retrospect, these primary treatment studies created a benchmark for IOP control with the added suggestion that better visual field preservation would be obtained as a result of IOPs (much) lower than the 'upper limit of normal'.

The consequence of the paper by Eddy and Billings was that non-IOP end points for chronic glaucoma needed to be established for the ensuing RCTs that assessed the possible benefits of IOP reduction. As I will discuss, difficulties with these end points have influenced much glaucoma research over the past 15 years.

\section{Changes since 1992}

It has been my privilege to be working in a busy eye hospital in a large glaucoma unit for the past 25 years, with the opportunity to collaborate with some of the finest minds conducting research in ophthalmology. Together we have witnessed some of the major changes in concept, causation, and control and have played a small part in each. This has been part phenomenological and part experimental. Those aspects of glaucoma that I will discuss will be:

(1) The size of the problem,

(2) the position of IOP, relative to elevation and fluctuation,

(3) ONH changes,

(4) visual function changes.

I will relate each of these to problems seen in but not necessarily specific to the United Kingdom.

\section{The size of the problem}

In the MRC Trial of the Assessment and Management of Older People in the Community, trial nurses tested visual acuity in everyone aged 75 years and older in 53 general practices. Data were obtained from 14600 participants aged 75 years and older. Prevalence of visual impairment overall (binocular visual acuity $<6 / 18$ ) that was categorized separately into low vision (binocular visual acuity $<6 / 18-3 / 60$ ) or blindness (binocular visual acuity of $<3 / 60){ }^{16}$

Visual acuity was available for 14600 people out of 21241 invited (69\%). Among people with visual acuity data, $12.4 \%$ overall (1803) were visually impaired; 1501 $(10.3 \%)$ were categorized as having low vision, and 302 (2.1\%) were blind.

At ages $75-79,6.2 \%$ of the cohort was visually impaired with $36.9 \%$ at age $90+$. At ages $75-79,0.6 \%$ of the study population was blind, with $6.9 \%$ at age $90+$.

If visual impairment had been defined as visual acuity of $<6 / 12$ (American definition of visual impairment), the age-specific prevalence estimates would have increased by $60 \%$.

The findings of this study were further refined. In total, $1742(12.5 \%)$ people visually impaired were found in the 49 participating practices. Of these, $450(26 \%)$ achieved a pinhole visual acuity in either eye of $6 / 18$ or better and were considered to have refractive error behind their reduced vision. The main cause of visual loss unrelated to refractive error was age-related macular degeneration (AMD);

$52.9 \%$ of people had AMD as a main or contributory

cause,

$35.9 \%$ had cataract,

$11.6 \%$ had glaucoma,

$4.2 \%$ had myopic degeneration,

$3.4 \%$ had diabetic eye disease. ${ }^{17}$

Similar figures have been provided from analysis of the CVI returns. ${ }^{18}$

In the United Kingdom, the estimated prevalence of OAG is $2.1 \%$, ranging from $0.3 \%$ in the 40 s to $3.3 \%$ in the 70s. The incidence ranges from 30 to 181 per 100000 person-years for ages 50 and 70, respectively. 
Approximately 500000 are estimated to suffer from glaucoma of which $67 \%$ are undetected (derived from pooled estimated of prevalence and incidence to the 2001 census data). The severity of disease at presentation was derived from cross-sectional studies. Mild disease ranges from 9 to $15 \%$, severe disease from 4 to $14 \%$, and blind form glaucoma ranged from 3 to $10 \%$. As will be discussed later, severe disease at presentation prejudices the chance of the patient from avoiding visual disability from glaucoma. ${ }^{19}$

Area and individual level deprivation were both associated with late presentation of glaucoma. Existing evidence shows that late presentation is an important risk factor for subsequent blindness. Deprived groups thus seem to be at greater risk of going blind from glaucoma. Material deprivation may be associated with more aggressive disease as well as later presentation. ${ }^{20}$ Factors in addition to deprivation associated with late presentation were African-Caribbean status, men $>$ women, non-optometric referral, low rather than high IOP, and increasing age. ${ }^{21}$

The cost of treating glaucoma rises with the stage of the disease. ${ }^{22} \mathrm{~A}$ fact mirrored by experience in the United States. ${ }^{23}$ As will be discussed later, late presentation also prejudices the chance of adequate visual preservation. Late presentation therefore occurs in certain groups of society, is more costly to treat, and makes the chance of visual disability higher despite treatment.

\section{Comment 1}

In the United Kingdom glaucoma is relatively common. In an aging population the numbers will rise disproportionately. Late presentation is related to socioeconomic factors and leads to greater costs and a poorer visual outcome.

\section{The position of IOP today}

The position of IOP in chronic glaucoma remains a Will$\mathrm{o}^{\prime}$-the-Wisp'. It has been progressively downgraded. Originally it was part of the definition of chronic glaucoma, then causative of the condition; now it is (only) a risk factor. Today we set Target Pressures as goals for successful treatment. Failure to 'control' IOP has been given as the cause of continuing progression of the disease. However without satisfactory end points independent of IOP, adequate duration of follow-up and good comparative groups, the role of IOP in chronic glaucoma has yet to be conclusively pinned down.

I will look at the following areas:

(1) IOP as a risk factor,

(2) IOP fluctuation,

(3) target IOPs.

\section{Intraocular pressure as a risk factor} Hollows and Graham ${ }^{24}$ showed from their population study in Wales that most individuals had an IOP of $17 \pm 3 \mathrm{~mm} \mathrm{Hg}$, yet a majority of the identified glaucoma's had an IOP exceeding this 'upper limit' of normal. The findings from this 'total population' study have been replicated elsewhere in other European populations. ${ }^{25-27}$

The prevalence of glaucoma was found to increase exponentially within defined IOP strata. ${ }^{28}$ Importantly, long-term incidence studies demonstrated the role of higher levels of IOP in the incident glaucoma cases, with

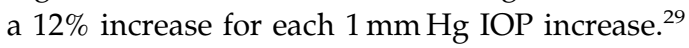

Additional important risk factors included pseudoexfoliation, and cup/disc (C/D) ratio. ${ }^{30}$ The benefits of IOP reduction in the ocular hypertensive patient was demonstrated in the Ocular Hypertension Treatment Study (OHTS). ${ }^{31}$

Although elevated IOP was seen as an important risk factor, it was recognized that there were many others. The Treatment/No Treatment Ocular Hypertension studies (OHTS and European Glaucoma Prevention Study (EGPS)) have demonstrated the multiplicity of these risk factors. ${ }^{32,33}$ These baseline 'risk factors' from the untreated arms of the two studies (EGPS and OHTS) have lead to a validated model of quantified 'risk'. These were: baseline age, IOP, central corneal thickness, vertical $\mathrm{C} / \mathrm{D}$ ratio, and Humphrey VF pattern standard deviation (SD). ${ }^{34}$ Caution has to be used when extrapolating the results from these RCTs to individual patients because of coexistent confounders in the latter that could have precluded entry into the trial as well as the statistical pitfalls of analysing patient group differences separated by only one variable. ${ }^{35}$

A similar protective effect of IOP reduction was shown by the Early Manifest Glaucoma Trial (EMGT), whereby patients in the treated arm were given treatment by argon laser trabeculoplasty and Betaxolol, supplemented with a prostaglandin for unacceptable increases in IOP. ${ }^{36}$ Predictive baseline factors were higher IOP (ie, the higher the baseline IOP, the higher the risk), exfoliation, and having both eyes eligible (each of the latter two factors doubled the risk), as well as worse mean deviation and older age. ${ }^{37}$

\section{Comment 2}

Elevated IOP is a risk factor for developing glaucoma and for its progression. Additional risk factors have been identified and weighted to better quantify risk for the individual patient.

Further risk factors, such as PEX, and IOP fluctuation have not been included in the predictive model for ocular hypertension at this time. Pseudoexfoliation was significantly associated with visual field progression in the EMGT study, but not identified in the OHT studies. 
Intraocular pressure fluctuation

There has been considerable interest paid in IOP fluctuation. It needs to be separated into diurnal (daytime) fluctuation, $24 \mathrm{~h}$ fluctuation, and long-term fluctuation. Diurnal fluctuation is increased in eyes with OHT, but not NTG. ${ }^{38,39}$ One long-term study that looked at diurnal IOP swings as an independent variable found that these fluctuations were not an independent risk factor for conversion to POAG. ${ }^{40}$

Sleep laboratory experiments show that in all subjects supine and nocturnal IOPs rise, although the swing was lower in eyes with a higher baseline IOP. ${ }^{41}$ However nocturnal $(24 \mathrm{~h})$ fluctuations may well contribute to the development of visual field progression in eyes with glaucoma damage, and measures to dampen such changes may offer additional protection.

Long-term fluctuation has been found to be a risk factor in a post hoc analysis of patients in the AIGS study for progression in glaucoma eyes with low mean IOP, but not a high mean IOP. ${ }^{42,43}$ Both increasing age and greater IOP fluctuation increase the odds of VF progression by $30 \%$ (for each 5-year increment in age and $1-\mathrm{mm} \mathrm{Hg}$ increase in IOP fluctuation). ${ }^{44}$ These findings could not be confirmed in the EMGT study, ${ }^{45}$ and this discrepancy may be explained in the analysis not including postprogression IOP measurements.

A retrospective review of two separate cohorts in the USA, each with mean IOP over the study period revealed that controlling for age, mean IOP, VF stage, and other covariates, each unit increase in IOP SD resulted in a 4.2 times and 5.5 times higher risk of glaucoma progression for cohort 1 (95\% confidence interval (CI): 1.3-12.9) and cohort 2 (95\% CI: 3.4-9.1), respectively. ${ }^{44}$ Another post hoc analysis, this time for patients in the EMGT did not confirm the above findings. One explanation for the discrepancy is that the analyses did not include post-progression IOP values, which would be biased towards larger fluctuations because of more intensive treatment. $^{45}$

Fluctuation is minimal after glaucoma surgery; however, for topical medication to be equally protective there needs to exert a similar degree of $24 \mathrm{~h}$ IOP control. Compliance and persistence studies suggest that this may be poor, increasing the risk of long-term IOP fluctuation and progression. ${ }^{46,47}$ Patients with low literacy can be less adherent with their glaucoma medications than those with a higher level of literacy. Interventions specifically targeting patients with low literacy may improve medication adherence. $^{48}$

For those eyes where diurnal and long-term fluctuation is considered to be a risk, and compliance a long-term problem surgery has been shown to flatten such IOP swings the most. ${ }^{13,49}$
Education of the patient is an essential part of glaucoma management. Failure to comply puts the glaucoma patient at long-term risk.

\section{Comment 3}

Long-term fluctuation is probably a risk factor for continued progression of glaucoma. Poor compliance with medication will increase this fluctuation and hence the risk.

Target intraocular pressures

The Moorfields Primary Treatment trial noted the difference in visual field outcome between the surgery and the other two groups. This could have been explained by a lower mean IOP over 5 years with $>4 \mathrm{~mm} \mathrm{Hg}$ difference, and also by lower diurnal IOP curves. ${ }^{13}$ Post hoc analysis from the AGIS trial also suggested different levels of visual field progression according to the IOP strata over the follow-up period as well as crucially for the first 6 months. ${ }^{50}$ The Moorfields 5-FU study prospectively looked at the visual field outcome in eyes stratified at different IOP levels and found that the best visual field protection occurred with eyes having IOPs in the low teens (PT Khaw personal communication).

In the EMGT study, analysis of patients for up to 11 years showed that post-baseline progression factors were IOP levels at follow-up (with 12-13\% average increase per millimetre of mercury in all patients), disc haemorrhages, and a thinner central corneal thickness (CCT) for patients with higher baseline IOP but not lower baseline IOP. Low perfusion pressure was also found to have significance. ${ }^{51}$

Comment 4

For glaucoma patients with baseline IOPs above the normal range, a target IOP in the mid teens is desirable. For glaucoma patients with baseline IOPs within the normal range, the Target IOP needs to be in the low 'teens'.

To be able to demonstrate a beneficial effect of treatment there needed to be defined and accepted nonIOP-related end points. These can be changes in the appearance of the optic disc, or in visual function, or in both.

\section{Optic nerve head recognition of change}

The RCTs were designed before any consensus had been reached on objective measures. As a consequence, RCTs relied on grouped observer agreement on sequential changes in the surface contour of the $\mathrm{ONH}$, by examining stereophotographs ${ }^{52}$ or stereochronoscopy. ${ }^{53}$ Observer 
agreement lead to end point recognition, even without the coincident development of SAP defects. ${ }^{54}$

However, man must measure. The failure to measure changes visible at the optic nerve head delayed the introduction of such changes into the range of viable end points in glaucoma treatment trials for decades. It was only the development of reliable imaging devices that raised the promise of using such changes. The past 15 years have seen a concerted effort in converting the observed changes into measurable ones. They have concentrated on (1) the separation of glaucoma from normal and (2) the detection of progression.

Methods chosen for these tasks have included planimetry, the scanning laser ophthalmoscope, the retinal nerve fibre layer analyser, and ocular computed tomography. Although each has specific merits, and any of the involved technologies could lead to an aid to routine clinical practice, at the present time the scanning laser ophthalmoscope, as marketed as the Heidelburg Retinal Tomograph (HRT), has the greatest body of investigative work.

A paper from Moorfields Eye hospital identified the linear relationship between the size of the optic disc and the log of the neuroretinal rim area. A cross-sectional study undertaken to separate 'normals' from early glaucoma (a total of 80 normal subjects and 51 patients with early glaucoma participated (average visual field mean deviation $=-3.6 \mathrm{~dB}$ )) was performed. The greatest sensitivity $(84.3 \%)$ and sensitivity $(96.3 \%)$ was found using the $99 \%$ prediction interval from the linear regression between the optic disc area and the log of the neuroretinal rim area. ${ }^{55}$ This work was extended by comparing the ability of expert observers looking at stereo photographs of 'early glaucomas' (average MD, $-3.6 \mathrm{db}$ ) and 'normals', the HRT. It was found that the HRT achieved better separation than the experts. ${ }^{56}$ Moorfields Regression Analysis (MRA) was incorporated into the Heidelburg software for general use. Subsequent studies verified its value, both in identifying visual field change $^{57}$ and in high-risk subjects in predicting their likely development. ${ }^{58}$ A subgroup from the OHTS had baseline SLO analysis. Eyes classified as 'outside normal limits' by the HRT classification and the MRA classifications (overall, global, temporal inferior, nasal inferior, and superior temporal regions) were significantly associated with the development of POAG. ${ }^{59}$

The HRT has been used as a screening tool with positive results, both in Canada ${ }^{60}$ and in Thailand (RR Bourne personal communication).

The major weakness in MRA has been observerdependant outlining of the margin of the optic disc. The more recent disc margin independent glaucoma probability score (GPS) that has scored equally well in discriminating between early glaucoma's and normals may provide a better way in the future. ${ }^{61,62}$

The ability of the SLO (or any other scanning device) to identify progressive glaucomatous changes at the optic disc is less well developed or agreed upon. At the present time, event analysis seems to have greater promise than trend analysis, so the ability to monitor change in progression with treatment remains limited. Moderate IOP reductions $(5 \mathrm{~mm} \mathrm{Hg}$ ) does not have detectable effect on optic disc topography. ${ }^{63-66}$

The inability of quantitative $\mathrm{ONH}$ analysis to identify rate of change also leads to difficulties in long-term management of chronic glaucoma, for, as will be discussed with visual fields, a change in RATE should be more informative than single event analysis in management.

\section{Comment 5}

Stereo-disc photographs are the current 'Gold

Standard' for monitoring disc change by event analysis. Quantifiable changes at the optic disc may replace this in the future. There are no methods for measuring rate of change available for clinical use at the present time.

There have been a number of longitudinal studies designed to look at the question whether changes can be detected first at the optic disc or the visual field. In the OHTS, 168 eyes of 152 ocular hypertensive participants' ages 40 to 80 years were studied. Of which, 41 eyes reached an end point by both VF and optic disc criteria; 40 eyes reached only a VF end point, and 87 reached only an optic disc end point. The time taken to reach isolated disc or field end points were similar. Visual field end points were more likely $(P<0.0001)$ in eyes that showed the following $\mathrm{ONH}$ features: an $\mathrm{ONH}$ haemorrhage, thinning of the optic disc rim, or enlargement of the horizontal $\mathrm{C} / \mathrm{D}$ ratio. Optic disc end points were more likely $(P<0.0001)$ in eyes that showed the following VF features: some evidence of a nasal step or a partial arcuate VF defect, or an increase in the pattern SD (PSD). ${ }^{67}$ Other studies looking at incident data in ocular hypertensives also showed poor correlation. ${ }^{68}$ Eyes with established glaucoma did not fare any differently, ${ }^{69}$ necessitating the need of both modalities for follow-up.

\section{Comment 6}

Baseline changes at the $\mathrm{ONH}$ may predict later SAP changes, and vice versa. Optic disc and visual field 'end points' indicating change can occur independently of one another. 
Visual field changes, the recognition of end points, and the concept of rate

The development of visual field end points as a primary outcome measures has proved difficult with no current consensus. Each RCT developed its own visual field end point, necessitated in part by the nature of the trial as well as the beliefs of the triallists. A useful comparison of the various methods by Vesti $e t a l^{70}$ using a simulated visual field series pointed out differences between these methods in time to detection and specificity. One essential difference was that some relied on event analysis and others used trend analysis. The former provides data on time to progression rather sooner; the latter provides a longer-term view on the effect of treatment. The former requires the establishment of a baseline (where the patient's performance could be said to be reproducible) against which performance at subsequent tests is compared. Trend makes use of repeated test points, uses all the data, and does not need a sequence of base line fields. It assumes progression is linear and that test points are independent of one another, neither of which may always be the case. Although trend analysis does make the assumption that change can be expressed linearly, this seems appropriate as it provides the best 'fit' in untreated visual field series. ${ }^{71}$ Analysis using pointwise linear progression agrees well with expert observers. ${ }^{72}$ The ability to subdivide the visual field into progressing sections rather than rely on median values is an advantage, for the latter will overlook small but significant changes even though the effects of lens opacities have been removed. ${ }^{73}$

Studies analysing rate of change have demonstrated the beneficial effects of IOP reduction in Normal-tension glaucoma, ${ }^{74}$ the post hoc analyses of the AGIS study, ${ }^{75}$ and may also have done so in the LOGTS study of normaltension glaucoma ${ }^{76}$ (an early study of the rate of change estimated rate of change by noticing the extent of visual loss at different pressure levels ${ }^{77}$ ).

\section{Comment 7}

Different methods of identifying visual field progression can be used for different purposes. Identifying RATE offers more chance of estimating disability over time.

All of these visual field studies are valuable for identifying change, rate of change, and the effect of treatment. To be able to use visual fields in glaucoma management requires resource utilization. To be of use in management, the frequency of visual field testing needs to be (usually) increased. From simulated field testing Gardiner and $\mathrm{Crabb}^{78}$ suggested three tests per year providing a good compromise between sensitivity and specificity. A more practical approach would be for frequent testing in the first 2 years to identify eyes with rapid progression despite treatment, followed by less frequent testing.

\section{Comment 8}

Visual field testing needs to be adapted to need and perceived level of disease control. Resource prioritization should be reviewed to allow greater emphasis on more frequent testing.

However, such testing can only be of value if it reflects the eventual outcome and the risk of visual disability. All studies that look at methods to detect 'preperimetric' change have no concept of the late effects of the disease on visual function. There is no data on the risk of visual disability from NOT identifying 'preperimetric' glaucoma. Risk analysis described earlier can only reflect such early change as recognized by event analysis. Natural history studies of untreated primary chronic glaucoma emphasize that a significant proportion of patients progress slowly, so slowly as to preclude detection of change within 5-year periods, although only $10 \%$ or so progress rapidly. ${ }^{79}$ Similar variability in time to progression was shown in the no-treatment arm of EMGT, and has been seen in the Moorfields Low Tension Clinic.

Known risk factors for progression account for about $50 \%$ of cases, these may be ocular or systemic related to ocular perfusion pressure. ${ }^{80}$

Late presentation carries a significant risk of visual disability, partly because the disease is more difficult to treat, but, more importantly because even slight progression can cause significant disability. A retrospective review of blindness in glaucoma patients showed that its occurrence despite good IOP control was associated with severity of visual loss at presentation. ${ }^{81-83}$

We understand a fair amount about eyes at risk, but because of the types of analyses are unable to state whether it is in the best interests of glaucoma patients to be diagnosed at the earliest possible opportunity, or whether it can be left until moderate visual field defects have developed. Without such information the issue comes down to cost. A significant confounding factor has to be life expectation. Early diagnosis might make more sense in the young, because even a slow rate of change could eventually produce disability, whereas co-morbidity restricting lifespan can mean that even late diagnosis has little visual effect. When assessing the type and vigorousness of treatment, or even whether to instigate treatment co-morbidity needs to be taken into account. One way of doing this is by using a measure of co-morbidity such as the Charlson index. The Charlson index is a popular method of assessing co-morbidity and has been 
shown to be a useful approach to risk adjustment in outcomes research. ${ }^{84,85}$

The index is used to predict life expectancy. Using points score weighting is given to coincident disease. Co-morbidities can be cumulative. It is a condition related weighting, points given from 1 to 6 . Examples of scores are set out below:

$1=\mathrm{MI} / \mathrm{CCF} /$ vascular disease $/$ diabetes, and so on $2=$ Hemiplegia/moderate renal disease/blood dyscrasias $3=$ Moderate $/$ severe liver disease

$6=$ AIDS $/$ metastatic tumour

Using the Charlson index to predict the likelihood of developing glaucoma gives very different predictions as increasing co-morbidity reduces life expectancy. An example of such a prediction is set out below:

75-year C/D (0.8), IOP (30), CCT (550), PSD (1.9)

5 -year risk - not accounting for co-morbidity (51\%)

$\begin{array}{ll}\text { Charlson index score } 0 & 46.9 \% \\ 1 & 41.8 \% \\ 2 & 32.4 \% \\ 3 & 32.4 \% \\ 4 & 10.7 \% \\ 5 & 6.5 \% \\ 6 & 6.0 \%\end{array}$

Combining ages and Charlson indices gives a variable risk for developing glaucoma, strongly influenced by the co-morbidity scores.

Studies on change in visual function have, correctly, focused on changes occurring in each eye. Monocular field loss only impinges when it abuts fixation. ${ }^{86}$ However overlapping visual fields (combined with an often slow rate of change and off centre initial loss) and cortical infilling means that the patient rarely notices visual loss until late in the disease. ${ }^{87}$

The challenge for the ophthalmologist is first to recognize that binocular defects have a significant effect on morbidity, producing significant visual disability, ${ }^{88,89}$ and second to assess rate of change in the binocular field. This process can be simplified by integrating the two monocular fields, either as best individual score ${ }^{90,91}$ or summation. ${ }^{92}$

Combining integrated visual fields with linear regression allows an estimation of time to visual disability however defined. The end point of disability would be a specific level of function on the binocular field. It could arbitrarily be set at a level where driving test standards would no longer be met, because loss of the driving licence has been voiced as a the major concern by glaucoma patients. ${ }^{93}$ A flexible level of disability has far greater relevance to the glaucoma patient, to different patient needs, and different patient populations than a universal definition of 'blindness' or visual impairment based on the vision in one or both eyes.

Comment 9

Binocular fields should be used as the yardstick of function, related to risk, and prediction of disability.

The challenge for ophthalmologists and other healthcare professionals is to ensure that visual disability however defined is avoided in the population. For an incurable group of diseases such as chronic glaucoma, this involves:

(1) Adequate identification of the patient at high risk of visual field loss,

(2) prevention of further visual loss by treatment,

(3) adequate monitoring of those diagnosed,

(4) appropriate treatment.

Finally, I will look into the future for glaucoma in the United Kingdom. As befits the Bowman lecturer this is a luxury given to any person reaching the end of his or her term, but who wishes to present their shoulders as a platform for nimble younger and brighter people to climb and from this vantage point go further into our speciality. I offer my shoulders for the following five challenges for UK glaucoma as directions for my nimbler colleagues to direct their gaze.

(1) For glaucoma detection to be successful it cannot afford to miss those least likely to be identified - the lower socioeconomic classes and the over busy. In a state-run system such as in the United Kingdom, the primary care providers should be made to capture ALL within their catchment area, to ensure that prophylactic case finding is available. The challenge is to ensure that this occurs.

(2) For glaucoma detection to be adopted in primary care there needs to be evidence of the disease level and type of case finding that can be undertaken and still be cost effective.

(3) For IOP reduction to be set at appropriate levels (targets), there needs to be an understanding of the trade-off between very low IOPs and resultant comorbidity on a case by case basis and how this changes with time, altered life expectancy, and visual needs.

(4) For non-IOP reduction treatment (neuroprotection), there needs to be clarity about end points of therapy with the development of believable surrogates for progression.

(5) There needs to be a wholesale transfer from the concept of monocular visual loss and 'blindness' to binocular visual loss and 'visual disability'. 


\section{References}

1 Henderson A. The anatomy of the so-called ligamentum pectinatum of the iris and its bearing on the physiology and the pathology of the eye. TOSUK 1908; 28: 47-59.

2 Duke-Elder S. Aetiology of simple glaucoma. TOSUK 1952; 67: 205-228.

3 Curran EJ. A new operation for glaucoma involving a new principle in the aetiology and treatment of primary glaucoma. Arch Ophthalmol 1920; 49: 131.

4 Troncosco M. Closure of the chamber angle in glaucoma. Arch Ophthalmol 1935; 14: 557.

5 Sugar HS. The Mechanical factors in the aetiology of acute glaucoma. Am J Ophthalmol 1941; 24: 851.

6 Haas J, Scheie HG. Peripheral iridectomy in narrow-angle glaucoma. Trans Am Acad Ophthalmol 1952; 56: 589.

7 Duke Elder S, Baranay HE, Goldmann H. Glaucoma: a Symposium. Organised by The Council for International Organisations of Medical Sciences established under the joint auspices of UNESCO and WHO. Blackwell Scientific Publications: Oxford. C Thomas Springfield, 1955.

8 Drance SM. Glaucoma-changing concepts. Eye 1992; 6: 337-345.

9 Leske MC, Heijl A, Hyman L, Bengtsson B, Dong L, Yang Z, EMGT Group. Predictors of long-term progression in the early manifest glaucoma trial. Ophthalmology 2007; 114(11): 1965-1972.

10 Leske MC, Wu SY, Hennis A, Honkanen R, Nemesure B, BESs Study Group. Risk factors for incident open-angle glaucoma: the Barbados Eye Studies. Ophthalmology 2008; 115(1): 85-93.

11 Eddy DM, Billings J. The quality of medical evidence and medical practice. Paper prepared for the national leadership commission on health care. Health Aff (Millwood) 1988; 7: 19-32.

12 Jay JL, Murray SB. Early trabeculectomy versus conventional management in primary open angle glaucoma. Br J Ophthalmol 1988; 72(12): 881-889.

13 Migdal C, Gregory W, Hitchings R. Long-term functional outcome after early surgery compared with laser and medicine in open-angle glaucoma. Ophthalmology 1994; 101(10): 1651-1656.

14 Musch DC, Lichter PR, Guire KE, Standardi CL. The Collaborative Initial Glaucoma Treatment Study: study design, methods, and baseline characteristics of enrolled patients. Ophthalmology 1999; 106(4): 653-662.

15 Lichter PR, Musch DC, Gillespie BW, Guire KE, Janz NK, Wren PA, et al., CIGTS Study Group. Interim clinical outcomes in the Collaborative Initial Glaucoma Treatment Study comparing initial treatment randomized to medications or surgery. Ophthalmology 2001; 108(11): 1943-1953.

16 Evans JR, Fletcher AE, Wormald RP, Ng ES, Stirling S, Smeeth $\mathrm{L}$ et al. Prevalence of visual impairment in people aged 75 years and older in Britain: results from the MRC trial of assessment and management of older people in the community. Br J Ophthalmol 2002; 86(7): 795-800.

17 Evans JR, Fletcher AE, Wormald RP. Causes of visual impairment in people aged 75 years and older in Britain: an add-on study to the MRC Trial of Assessment and Management of Older People in the Community. MRC Trial of Assessment and Management of Older People in the Community. Br J Ophthalmol 2004; 88(3): 365-370.

18 Bunce C, Wormald R. Leading causes of certification for blindness and partial sight in England and Wales. BMC Public Health 2006; 6: 58.
19 Burr JM, Mowatt G, Hernández R, Siddiqui MA, Cook J, Lourenco $T$ et al. The clinical effectiveness and costeffectiveness of screening for open angle glaucoma: a systematic review and economic evaluation. Health Technol Assess 2007; 11(41): 1-190. Review.

20 Fraser S, Bunce C, Wormald R, Brunner E. Deprivation and late presentation of glaucoma: case-control study. BMJ 2001; 322(7287): 639-643.

21 Fraser S, Bunce C, Wormald R. Retrospective analysis of risk factors for late presentation of chronic glaucoma. $\mathrm{Br} J$ Ophthalmol 1999; 83(1): 24-28.

22 Traverso CE, Walt JG, Kelly SP, Hommer AH, Bron AM, Denis $\mathrm{P}$ et al. Direct costs of glaucoma and severity of the disease: a multinational long term study of resource utilisation in Europe. Br J Ophthalmol 2005; 89(10): 1245-1249.

23 Lee PP, Kelly SP, Mills RP, Traverso CE, Walt JG, Doyle JJ, Costs of Glaucoma Study Group et al. Glaucoma in the United States and Europe: predicting costs and surgical rates based upon stage of disease. J Glaucoma 2007; 16(5): 471-478.

24 Hollows FC, Graham PA. Intra-ocular pressure, glaucoma, and glaucoma suspects in a defined population. Br J Ophthalmol 1966; 50(10): 570-586.

25 Bonomi L, Marchini G, Marraffa M, Bernardi P, De Franco I, Perfetti $S$ et al. Prevalence of glaucoma and intraocular pressure distribution in a defined population. The Egna-Neumarkt Study. Ophthalmology 1998; 105(2): 209-215.

26 Nizankowska MH, Kaczmarek R. Prevalence of glaucoma in the wroclaw population. The wroclaw epidemiological study. Ophthalmic Epidemiol 2005; 12(6): 363-371.

27 de Voogd S, Ikram MK, Wolfs RC, Jansonius NM, Hofman A, de Jong PT. Incidence of open-angle glaucoma in a general elderly population: the Rotterdam Study. Ophthalmology 2005; 112(9): 1487-1493.

28 Sommer A, Tielsch JM, Katz J, Quigley HA, Gottsch JD, Javitt $\mathrm{J}$ et al. Relationship between intraocular pressure and primary open angle glaucoma among White and Black Americans. The Baltimore Eye Survey. Arch Ophthalmol 1991; 109(8): 1090-1095.

29 Nemesure B, Honkanen R, Hennis A, Wu SY, Leske MC. Incident open-angle glaucoma and intraocular pressure; Barbados Eye Studies Group. Ophthalmology 2007; 114(10): 1810-1815.

30 Le A, Mukesh BN, McCarty CA, Taylor HR. Risk factors associated with the incidence of open-angle glaucoma: the visual impairment project. Invest Ophthalmol Vis Sci 2003; 44(9): 3783-3789.

31 Kass MA, Heuer DK, Higginbotham EJ, Johnson CA, Keltner JL, Miller JP et al. The Ocular Hypertension Treatment Study: a randomized trial determines that topical ocular hypotensive medication delays or prevents the onset of primary open-angle glaucoma. Arch Ophthalmol 2002; 120(6): 701-713.

32 Gordon MO, Beiser JA, Brandt JD, Heuer DK, Higginbotham EJ, Johnson CA et al. The Ocular Hypertension Treatment Study: baseline factors that predict the onset of primary open-angle glaucoma. Arch Ophthalmol 2002; 120(6): 714-720.

33 Miglior S, Pfeiffer N, Torri V, Zeyen T, Cunha-Vaz J, Adamsons I, European Glaucoma Prevention Study (EGPS) Group. Predictive factors for open-angle glaucoma among patients with ocular hypertension in the European 
Glaucoma Prevention Study. Ophthalmology 2007; 114(1): 3-9.

34 Gordon MO, Torri V, Miglior S, Beiser JA, Floriani I, Miller JP et al. Validated prediction model for the development of primary open-angle glaucoma in individuals with ocular hypertension. Ocular Hypertension Treatment Study Group and European Glaucoma Prevention Study Group. Ophthalmology 2007; 114(1): 10-19.

35 Kent DM, Hayward RA. Limitations of applying summary results of clinical trials to individual patients the need for risk stratification. JAMA 2007; 298: 1209-1212.

36 Heijl A, Leske MC, Bengtsson B, Hyman L, Bengtsson B, Hussein M. Reduction of intraocular pressure and glaucoma progression: results from the Early Manifest Glaucoma Trial. Early Manifest Glaucoma Trial Group. Factors slowing or halting progression involved reducing IOP. Arch Ophthalmol 2002; 120(10): 1268-1279.

37 Leske MC, Heijl A, Hussein M, Bengtsson B, Hyman L, Komaroff E. Factors for glaucoma progression and the effect of treatment: the early manifest glaucoma trial. Early Manifest Glaucoma Trial Group. Arch Ophthalmol 2003; 121(1): 48-56.

38 De Vivero C, O’Brien C, Lanigan L, Hitchings R. Diurnal intraocular pressure variation in low-tension glaucoma. Eye 1994; 8(Part 5): 521-523.

39 Shuba LM, Doan AP, Maley MK, Zimmerman MB, Dinn RB, Greenlee EC et al. Diurnal fluctuation and concordance of intraocular pressure in glaucoma suspects and normal tension glaucoma patients. Glaucoma 2007; 16(3): 307-312.

40 Bengtsson B, Heijl A. Diurnal IOP fluctuation: not an independent risk factor for glaucomatous visual field loss in high-risk ocular hypertension. Graefes Arch Clin Exp Ophthalmol 2005; 243(6): 513-518.

41 Liu JH, Zhang X, Kripke DF, Weinreb RN. Twenty-four-hour intraocular pressure pattern associated with early glaucomatous changes. Invest Ophthalmol Vis Sci 2003; 44(4): 1586-1590.

42 Medeiros FA, Weinreb RN, Zangwill LM, Alencar LM, Sample PA, Vasile C et al. Long-term intraocular pressure fluctuations and risk of conversion from ocular hypertension to glaucoma. Ophthalmology 2007; 115(6): 934-940.

43 Nouri-Mahdavi K, Hoffman D, Coleman AL, Liu G, Li G, Gaasterland D, et al., Advanced Glaucoma Intervention Study. Predictive factors for glaucomatous visual field progression in the Advanced Glaucoma Intervention Study. Ophthalmology 2004; 111(9): 1627-1635.

44 Caprioli J, Coleman AL. Intraocular pressure fluctuation a risk factor for visual field progression at low intraocular pressures in the Advanced Glaucoma Intervention Study. Ophthalmology 2008; 115(7): 1123-1129.

45 Bengtsson B, Leske MC, Hyman L, Heijl A, Early Manifest Glaucoma Trial Group. Fluctuation of intraocular pressure and glaucoma progression in the early manifest glaucoma trial. Ophthalmology 2007; 114(2): 205-209.

46 Lee PP, Walt JW, Rosenblatt LC, Siegartel LR, Stern LS. Association between intraocular pressure variation and glaucoma progression: data from a United States chart review Glaucoma Care Study Group. Am J Ophthalmol 2007; 144(6): 901-907.

47 Lee PP, Walt JG, Chiang TH, Guckian A, Keener J. A gap analysis approach to assess patient persistence with glaucoma medication. Am J Ophthalmol 2007; 144(4): 520-524.

48 Muir KW, Santiago-Turla C, Stinnett SS, Herndon LW, Allingham RR, Challa P et al. Health literacy and adherence to glaucoma therapy. Am J Ophthalmol 2006; 142(2): 223-226.

49 Medeiros FA, Pinheiro A, Moura FC, Leal BC, Susanna Jr R. Intraocular pressure fluctuations in medical versus surgically treated glaucomatous patients. J Ocul Pharmacol Ther 2002; 18(6): 489-498.

50 The AGIS Investigators The Advanced Glaucoma Intervention Study (AGIS): 7. The relationship between control of intraocular pressure and visual field deterioration. Am J Ophthalmol 2000; 130(4): 429-440.

51 Leske MC, Heijl A, Hyman L, Bengtsson B, Dong L, Yang Z, EMGT Group. Predictors of long-term progression in the early manifest glaucoma trial. Ophthalmology 2007; 114(11): 1965-1972.

52 Feuer WJ, Parrish II RK, Schiffman JC, Anderson DR, Budenz DL, Wells MC et al. The Ocular Hypertension Treatment Study: reproducibility of cup/disk ratio measurements over time at an optic disc reading center Am J Ophthalmol 2002; 133(1): 19-28.

53 Leske MC, Heijl A, Hyman L, Bengtsson B. Early manifest glaucoma trial: design and baseline data. Ophthalmology 1999; 106(11): 2144-2153.

54 Kass MA, Heuer DK, Higginbotham EJ, Johnson CA, Keltner JL, Miller JP et al. The Ocular Hypertension Treatment Study: a randomized trial determines that topical ocular hypotensive medication delays or prevents the onset of primary open-angle glaucoma. Arch Ophthalmol 2002; 120(6): 701-713.

55 Wollstein G, Garway-Heath DF, Hitchings RA. Identification of early glaucoma cases with the scanning laser ophthalmoscope. Ophthalmology 1998; 105(8): 1557-1563.

56 Wollstein G, Garway-Heath DF, Fontana L, Hitchings RA. Identifying early glaucomatous changes. Comparison between expert clinical assessment of optic disc photographs and confocal scanning ophthalmoscopy. Ophthalmology 2000; 107(12): 2272-2277.

57 Miglior S, Guareschi M, Albe' E, Gomarasca S, Vavassori M, Orzalesi N. Detection of glaucomatous visual field changes using the Moorfields regression analysis of the Heidelberg retina tomograph. Am J Ophthalmol 2003; 136(1): 26-33.

58 Bowd C, Zangwill LM, Medeiros FA, Hao J, Chan K, Lee TW et al. Confocal scanning laser ophthalmoscopy classifiers and stereophotograph evaluation for prediction of visual field abnormalities in glaucoma-suspect eyes. Invest Ophthalmol Vis Sci 2004; 45(7): 2255-2262.

59 Zangwill LM, Weinreb RN, Beiser JA, Berry CC, Cioffi GA, Coleman AL et al. Baseline topographic optic disc measurements are associated with the development of primary open-angle glaucoma: the Confocal Scanning Laser Ophthalmoscopy Ancillary Study to the Ocular Hypertension Treatment Study. Arch Ophthalmol 2005; 123(9): 1188-1197.

60 Harasymowycz PJ, Papamatheakis DG, Fansi AK, Gresset J, Lesk MR. Validity of screening for glaucomatous optic nerve damage using confocal scanning laser ophthalmoscopy (Heidelberg Retina Tomograph II) in highrisk populations: a pilot study. Ophthalmology 2005; 112(12): 2164-2171.

61 Moreno-Montañés J, Antón A, García N, Mendiluce L, Ayala E, Sebastián A. Glaucoma probability score vs 
moorfields classification in normal, ocular hypertensive, and glaucomatous eyes. Am J Ophthalmol 2008; 145(2): 360-368.

62 Zangwill LM, Jain S, Racette L, Ernstrom KB, Bowd C, Medeiros FA et al. The effect of disc size and severity of disease on the diagnostic accuracy of the Heidelberg Retina Tomograph Glaucoma Probability Score. Invest Ophthalmol Vis Sci 2007; 48(6): 2653-2660.

63 Nicolela MT, Soares AS, Carrillo MM, Chauhan BC, LeBlanc $\mathrm{RP}$, Artes PH. Effect of moderate intraocular pressure changes on topographic measurements with confocal scanning laser tomography in patients with glaucoma. Arch Ophthalmol 2006; 124(5): 633-640.

64 Chauhan BC, McCormick TA, Nicolela MT, LeBlanc RP. Optic disc and visual field changes in a prospective longitudinal study of patients with glaucoma: comparison of scanning laser tomography with conventional perimetry and optic disc photography. Arch Ophthalmol 2001; 119(10): 1492-1499.

65 Chauhan BC, Blanchard JW, Hamilton DC, LeBlanc RP. Technique for detecting serial topographic changes in the optic disc and peripapillary retina using scanning laser tomography. Invest Ophthalmol Vis Sci 2000; 41(3): 775-782.

66 Fayers T, Strouthidis NG, Garway-Heath DF. Monitoring glaucomatous progression using a novel Heidelberg Retina Tomograph event analysis. Ophthalmology 2007; 114(11): 1973-1980.

67 Keltner JL, Johnson CA, Anderson DR, Levine RA, Fan J, Cello KE, et al., Ocular Hypertension Treatment Study Group. The association between glaucomatous visual fields and optic nerve head features in the Ocular Hypertension Treatment Study. Ophthalmology 2006; 113(9): 1603-1612.

68 Strouthidis NG, Scott A, Peter NM, Garway-Heath DF. Optic disc and visual field progression in ocular hypertensive subjects: detection rates, specificity, and agreement. Invest Ophthalmol Vis Sci 2006; 47(7): 2904-2910.

69 Artes PH, Chauhan BC. Longitudinal changes in the visual field and optic disc in glaucoma. Prog Retin Eye Res 2005; 24(3): 333-354.

70 Vesti E, Johnson CA, Chauhan BC. Comparison of different methods for detecting glaucomatous visual field progression. Invest Ophthalmol Vis Sci 2003; 44(9): 3873-3879.

71 McNaught AI, Crabb DP, Fitzke FW, Hitchings RA. Modelling series of visual fields to detect progression in normal-tension glaucoma. Graefes Arch Clin Exp Ophthalmol 1995; 233(12): 750-755.

72 Viswanathan AC, Crabb DP, McNaught AI, Westcott MC, Kamal D, Garway-Heath DF et al. Interobserver agreement on visual field progression in glaucoma: a comparison of methods. Br J Ophthalmol 2003; 87(6): 726-730.

73 Bengtsson B, Heijl A. A visual field index for calculation of glaucoma rate of progression. Am J Ophthalmol 2008; 145(2): 343-353.

74 Bhandari A, Crabb DP, Poinoosawmy D, Fitzke FW, Hitchings RA, Noureddin BN. Effect of surgery on visual field progression in normal-tension glaucoma. Ophthalmology 1997; 104(7): 1131-1137.

75 Nouri-Mahdavi K, Caprioli J, Coleman AL, Hoffman D, Gaasterland D. Pointwise linear regression for evaluation of visual field outcomes and comparison with the advanced glaucoma intervention study methods. Arch Ophthalmol 2005; 123(2): 193-199.

76 Krupin T, Liebmann JM, Greenfield DS, Rosenberg LF, Ritch R, Yang JW. The Low-pressure Glaucoma Treatment Study
(LoGTS) study design and baseline characteristics of enrolled patients. Low-Pressure Glaucoma Study Group. Ophthalmology 2005; 112(3): 376-385.

77 Jay JL, Murdoch JR. The rate of visual field loss in untreated primary open angle glaucoma. Br J Ophthalmol 1993; 77(3): 176-178.

78 Gardiner SK, Crabb DP. Frequency of testing for detecting visual field progression. Br J Ophthalmol 2002; 86(5): 560-564.

79 Anderson DR, Drance SM, Schulzer M. Natural history of normal-tension glaucoma. Collaborative Normal-Tension Glaucoma Study Group. Ophthalmology 2001; 108(2): 247-253.

80 Leske MC, Heijl A, Hyman L, Bengtsson B, Dong L, Yang Z. EMGT Group Predictors of long-term progression in the early manifest glaucoma trial. Ophthalmology 2007; 114(11): 1965-1972.

81 Oliver JE, Hattenhauer MG, Herman D, Hodge DO, Kennedy R, Fang-Yen $\mathrm{M}$ et al. Blindness and glaucoma: a comparison of patients progressing to blindness from glaucoma with patients maintaining vision. Am J Ophthalmol 2002; 133(6): 764-772.

82 Chen PP. Blindness in patients with treated open-angle glaucoma. Ophthalmology 2003; 110(4): 726-733.

83 Ehrnrooth P, Puska P, Lehto I, Laatikainen L. Progression of visual field defects and visual loss in trabeculectomized eyes. Graefes Arch Clin Exp Ophthalmol 2005; 243(8): 741-747.

84 Schneeweiss S, Maclure M. Use of comorbidity scores for control of confounding in studies using administrative databases. Int J Epidemiol 2000; 29(5): 891-898.

85 D'Hoore W, Sicotte C, Tilquin C. Risk adjustment in outcome assessment: the Charlson comorbidity index. Methods Inf Med 1993; 32(5): 382-387.

86 Membrey WL, Poinoosawmy DP, Bunce C, Fitzke FW, Hitchings RA. Comparison of visual field progression in patients with normal pressure glaucoma between eyes with and without visual field loss that threatens fixation. Br J Ophthalmol 2000; 84(10): 1154-1158.

87 Hoste AM. New insights into the subjective perception of visual field defects. Bull Soc Belge Ophtalmol 2003; (287): 65-71.

88 Ramrattan RS, Wolfs RC, Panda-Jonas S, Jonas JB, Bakker D, Pols HA et al. Prevalence and causes of visual field loss in the elderly and associations with impairment in daily functioning: the Rotterdam Study. Arch Ophthalmol 2001; 119(12): 1788-1794.

89 Johnson CA, Keltner JL. Incidence of visual field loss in 20000 eyes and its relationship to driving performance. Arch Ophthalmol 1983; 101(3): 371-375.

90 Crabb DP, Viswanathan AC. Integrated visual fields: a new approach to measuring the binocular field of view and visual disability. Graefes Arch Clin Exp Ophthalmol 2005; 243(3): 210-216.

91 Chisholm CM, Rauscher FG, Crabb DC, Davies LN, Dunne $\mathrm{M}$, Edgar DF et al. Assessing visual fields for driving in patients with paracentral scotomata. Br J Ophthalmol 2008; 92(2): 225-230.

92 Nelson-Quigg JM, Cello K, Johnson CA. Predicting binocular visual field sensitivity from monocular visual field results. Invest Ophthalmol Vis Sci 2000; 41(8): 2212-2221.

93 Bhargava JS, Patel B, Foss AJ, Avery AJ, King AJ. Views of glaucoma patients on aspects of their treatment: an assessment of patient preference by conjoint analysis. Invest Ophthalmol Vis Sci 2006; 47(7): 2885-2888. 